\title{
Study on water stability of asphalt binder with medium weathered igneous rock
}

\author{
Changgui $\mathrm{Li}^{1}$, Yuanhong Tao ${ }^{1, *}$, Jingliang $\mathrm{Xia}^{2,3,4}$ \\ ${ }^{1}$ China Road and Bridge Co., Beijing 100011, China \\ ${ }^{2}$ China Academy of Building Research, Beijing 100013, China \\ ${ }^{3}$ National Engineering Research Center of Building Technology, Beijing 100013, China \\ ${ }^{4}$ State Key Laboratory of Building Safety and Built Environment, Beijing 100013, China
}

\begin{abstract}
Aiming at the problems of weak acidity of medium weathered igneous rock around Nairobi, Kenya, poor adhesion with asphalt and poor water stability of asphalt binder, the article studied the use of antistripping agent, cement, hydrated Lime and other technical measures to improve the water stability of asphalt binder with medium weathered igneous rock. The results showed that the $48 \mathrm{~h}$ Marshall residual stability of the benchmark asphalt binder without any measures was $78.5 \%$, which did not meet the standard requirements. The Marshall residual stability of medium weathered igneous rock can be significantly improved by adding anti stripping agent, cement and hydrated Lime. After freeze-thaw cycles, the splitting tensile strength of the asphalt binder with medium weathered igneous rock decreased obviously, and the TSR values of the asphalt binder with anti-spalling measures from small to large were K-4, K-3, K-2, K-6 and K-5. The water stability of the medium weathered igneous rock asphalt binder mixed with anti-stripping agent alone had relatively poor durability, and the medium weathered igneous rock asphalt binder mixed with cement and anti-stripping agent had the strongest ability to resist deformation when immersed in water.
\end{abstract}

\section{Introduction}

China is pursuing the "Belt and Road" construction. The Nairobi Expressway in Kenya is one of the important infrastructure projects in East Africa. The main line of the expressway has a total length of $27 \mathrm{~km}$ and a design speed of 80 kilometers per hour, which is a national highway Aclass highway. The rocks in Nairobi and surrounding areas are mainly medium weathered igneous rock. After investigation, the medium weathered igneous rock available along the project are weakly acidic aggregates, and other rock quarries are far away and costly. The project considers using medium weathered igneous rock along the highway for engineering construction.

Since medium weathered igneous rock is weakly acidic aggregate, and asphalt is also acidic, the adhesion of asphalt and aggregate needs to be studied. In the application of acidic aggregates, Dong et al. [1] studied the adhesion of lime to asphalt and granite aggregates and found that lime could increase the surface energy of asphalt and enhance the adhesion work between asphalt and granite aggregates, thereby improving adhesion; the adhesion of asphalt and granite aggregate increased with the increase of lime fineness; when the lime content was $10 \%$ of the asphalt mass, the adhesion between asphalt and granite aggregate was the best. Tan et al. [2-7] studied to improve the adhesion of asphalt and acidic rocks by adding anti-stripping agent, cement, etc., thereby improving the water stability performance. The research results also showed that different technical measures have improved the adhesion of asphalt and aggregate to a certain extent.

However, the investigation of domestic and foreign related research showed that there were few reports on the adhesion of medium weathered igneous rock and asphalt, especially the water stability. In order to promote the application of medium weathered igneous rock in the Nairobi Expressway in Kenya, this research used the test methods such as the immersion Marshall test, the split strength test after freezing and thawing, and the water rutting test to investigate the improvement of antistripping agent, cement, hydrated Lime and other materials on the water stability of asphalt binder with medium weathered igneous rock.

\section{Material and testing method}

\subsection{Raw material}

(1) Aggregate: The aggregate used in this experiment was medium weathered igneous rock in Nairobi and surrounding areas. The rock was processed into coarse and fine aggregates using a laboratory small jaw crusher.

\footnotetext{
Corresponding author: taoyh@crbc.com
} 
For stone powder with a particle size of $0 \sim 0.075 \mathrm{~mm}$, chemical titration was used for chemical composition analysis. According to Chinese Standard the Methods of Aggregate for Highway Engineering (JTG E42-2005), the compressive strength, apparent density, firmness, and crush value of aggregates with a particle size of $5-25 \mathrm{~mm}$ were tested, and the test results were shown in Table 1:

Table 1 Technical indicators of aggregate

\begin{tabular}{|c|c|c|}
\hline \multirow{4}{*}{ Oxide composition/\% } & $\mathrm{SiO}_{2}$ & 65.39 \\
\cline { 2 - 3 } & $\mathrm{Al}_{2} \mathrm{O}_{3}$ & 13.18 \\
\cline { 2 - 3 } & $\mathrm{Fe}_{2} \mathrm{O}_{3}$ & 12.27 \\
\cline { 2 - 3 } & $\mathrm{CaO}$ & 2.66 \\
\cline { 2 - 3 } & $\mathrm{MgO}$ & 0.82 \\
\hline \multicolumn{2}{|c|}{ Compressive strength $(\mathrm{MPa})$} & 95.2 \\
\hline \multicolumn{2}{|c|}{ Apparent density $\left(\mathrm{kg} \cdot \mathrm{m}^{-3}\right)$} & 2672 \\
\hline \multicolumn{2}{|c|}{ Crush value (\%) } & 10.15 \\
\hline \multicolumn{2}{|c|}{ Robustness (\%) } & 3.2 \\
\hline
\end{tabular}

(2) Asphalt: The asphalt used in this test was road petroleum asphalt 90\#, and its technical indicators were shown in Table 2:

Table 2 Technical indicators of asphalt

\begin{tabular}{|c|c|c|}
\hline $\begin{array}{c}\text { Penetration at } 25^{\circ} \mathrm{C} \\
(0.1 \mathrm{~mm})\end{array}$ & $\begin{array}{c}\text { Softening point } \\
\left({ }^{\circ} \mathrm{C}\right)\end{array}$ & $\begin{array}{c}\text { Ductility }\left(15^{\circ} \mathrm{C},\right. \\
5 \mathrm{~cm} / \mathrm{min})\end{array}$ \\
\hline 95.6 & 47.2 & 145.1 \\
\hline
\end{tabular}

(3) Cement: CEM I 42.5 cement produced locally in Kenya was used. The setting time is $165 \mathrm{~min}$ for initial setting and $267 \mathrm{~min}$ for final setting. Water consumption for standard consistency is $26 \%, 3 \mathrm{~d}$ compressive strength is $27.1 \mathrm{MPa}$, $28 \mathrm{~d}$ compressive strength is $52.3 \mathrm{MPa}$.

(4) Hydrated Lime: hydrated Lime produced locally in Kenya with an effective $\mathrm{CaO}$ and $\mathrm{MgO}$ content of $68.2 \%$ was used.

(5) Amine anti-stripping agent: liquid amine antistripping agent was used, whose appearance is milky white thick liquid, $\mathrm{pH}$ value is between 10 and 12 , and freezing point is less than $0{ }^{\circ} \mathrm{C}$. And its content is $0.4 \%$ of the asphalt mass.

\subsection{Testing Proportion}

In order to study and improve the road performance of medium weathered igneous rock asphalt binder, antistripping agent, cement, hydrated Lime, and Compound of anti-stripping agent, cement and hydrated Lime were used as admixtures to study their influence on the water stability of asphalt binder. The amount of slag powder accounts for $2 \%$ of the total amount of ore; the blending amounts of cement and hydrated Lime account for $50 \%$ of the total amount of slag powder. When used alone, the amount of anti-stripping agent was $0.3 \%$ of the asphalt content; when it was compounded with cement and hydrated Lime, the amount of anti-stripping agent was $0.2 \%$ of the amount of asphalt, and cement and hydrated Lime respectively account for $50 \%$ of the amount of slag powder.

Table 3 Proportion of ore materials

\begin{tabular}{|c|c|c|c|c|}
\hline Sample number & Slag powder (\%) & Anti-stripping agent (\%) & Cement (\%) & Hydrated Lime (\%) \\
\hline K-1 & 2 & - & - & - \\
\hline K-2 & 2 & 0.3 & - & - \\
\hline K-3 & 1 & - & 1 & - \\
\hline K-4 & 1 & - & - & 1 \\
\hline K-5 & 1 & 0.2 & 1 & - \\
\hline K-6 & 1 & 0.2 & - & 1 \\
\hline
\end{tabular}

\subsection{Testing method}

At present, the evaluation methods for the water stability of asphalt binder mainly include the immersion Marshall test, the split strength test after freezing and thawing, and the water immersion rutting test. The split strength test after freezing and thawing and the water immersion rutting test are in accordance with Chinese Standard Test Method of Bitumen and Bituminous Mixtures for Highway Engineering (JTU E20-2011). Based on this standard, the immersion Marshall test was adjusted. Specifically, on the basis of the conventional Marshall stability test, the immersion time was extended to $0.5 \mathrm{~h}$, $48 \mathrm{~h}, 72 \mathrm{~h}, 96 \mathrm{~h}$, respectively, to test the Marshall stability after immersion, and calculate the residual stability of different immersion times.

\section{Result and discussion}

\subsection{The immersion Marshall test}

The main reason of water damage and poor water stability of asphalt binder pavement structure is the decrease of adhesion between asphalt and aggregate. The reason for the decrease of adhesion is that water enters between asphalt and aggregate, which makes the adhesion between asphalt and aggregate decrease until asphalt is separated from aggregate surface. On the other hand, the binding force of water and aggregate is greater than that of asphalt and aggregate, so it can break off the bonding between asphalt and aggregate, and make asphalt separate from aggregate surface. Therefore, the immersion Marshall test was used to evaluate the water stability of the asphalt binder.

The test results of Marshall stability and residual stability of different test schemes for improving the bonding performance of asphalt and aggregate were 
shown in Figure 1 and Figure 2. It could be seen that the Marshall stability of the different test groups gradually decreased with the increase of the immersion time of the test piece. The $48 \mathrm{~h}$ Marshall residual stability of the K-1 test group without any measures was $78.5 \%$, which did not meet the requirements of Technical Specifications for Construction of Highway Asphalt Pavements JTG F402017 to be higher than $80 \%$, and the Marshall stability cannot be measured after the test piece is immersed in water 96h. Therefore, it was clear that for medium weathered igneous rock, appropriate anti-stripping measures need to be taken when used in asphalt binders.

Combining Figure 1 and Figure 2, it could be seen that under different immersion times, the Marshall stability of the K-2 to K-6 groups were significantly higher than that of the K-1 group, indicating that different technical methods had a certain effect on improving the water stability of the medium weathered igneous rock asphalt binder. Comparing different technical measures, it could be found that the Marshall stability of the asphalt binder mixed with the anti-stripping agent alone was not much different from other technical measures at the immersion time of $48 \mathrm{~h}$, but when the immersion time reached $96 \mathrm{~h}$, the Marshall stability of K-2 has a significant decrease. The main reason was that the anti-stripping agent is a liquid amine, which is organic, and its anti-aging performance is relatively poor, and the anti-stripping effect becomes weak during long-term immersion. Hence, it was recommended to use cement or hydrated Lime, or a combination of cement, hydrated Lime and antistripping agent, for the medium weathered igneous rock asphalt binder, which can improve the water stability of the asphalt binder for a long time.

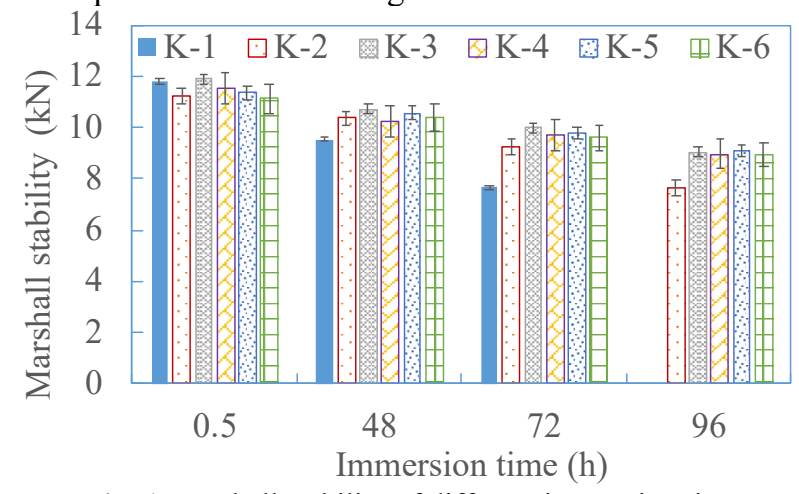

Fig. 1 Marshall stability of different immersion time

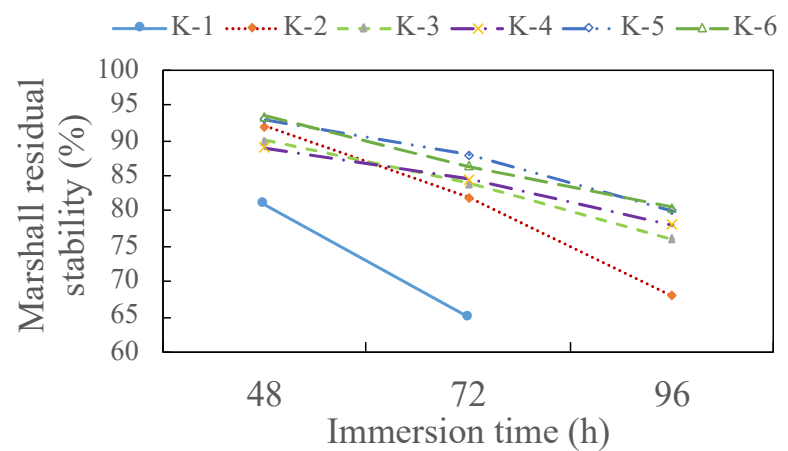

Fig. 2 Marshall Residual Stability of Different Immersion time

\subsection{Freeze-thaw test}

The main reason for the water damage of asphalt binder pavement structure and poor water stability of asphalt binder is not only the decrease of the adhesion between asphalt and aggregate, but also the existence of the water between asphalt and aggregate, which is prone to hydrodynamic pressure. This repeatedly acts on the interface between asphalt and aggregate, causing aggregate detachment in the asphalt-bound material pavement structure, forming potholes and other pavement diseases. For this reason, the study uses the splitting tensile strength of the asphalt binder after freezing and thawing to compare the splitting tensile strength of the asphalt binder without freezing and thawing to evaluate the water stability of the weathered igneous rock asphalt binder.

The test results of freeze-thaw splitting tensile strength and splitting tensile strength ratio (TSR) of different test schemes to improve the binding performance of asphalt and aggregate were shown in Fig. 3 and Fig. 4. It could be seen that the splitting tensile strength of medium weathered igneous rock asphalt binder decreased significantly after freeze-thaw cycle, and the TSR of the benchmark test group k-1 without any measures was only $67.1 \%$, which did not meet the requirement of more than $75 \%$ in JTG F40-2017. Therefore, it was necessary to take corresponding technical measures to improve the water stability when the medium weathered igneous rock is applied in asphalt binder.

It could be seen from Figure 4 that the TSR values of asphalt binders with anti-spalling technical measures from small to large were K-4 (hydrated Lime accounts for 50\% of mineral powder), K-3 (cement accounts for $50 \%$ of mineral powder), K-2 ( $0.3 \%$ of asphalt), K-6 $(0.2 \%$ of anti-spalling agent combined with hydrated Lime), K-5 ( $0.2 \%$ of anti-spalling agent combined with cement). The TSR values of asphalt binders of K-2 to K-6 could meet the requirements of JTG F40-2017, in which the minimum TSR value of asphalt binders with single hydrated Lime were $79.2 \%$, the maximum TSR value of asphalt binders with anti-stripping agent $0.2 \%$ and cement compound technical measures was $87.3 \%$. In general, the single addition of anti-stripping agent, cement or hydrated Lime can greatly improve the TSR of medium weathered igneous rock asphalt binder. The single addition of antistripping agent had the best effect, and the single addition of cement was better than hydrated Lime. In addition, through the combination of anti-stripping agent and cement or hydrated Lime, the water stability of weathered igneous rock asphalt binder was improved most significantly. 


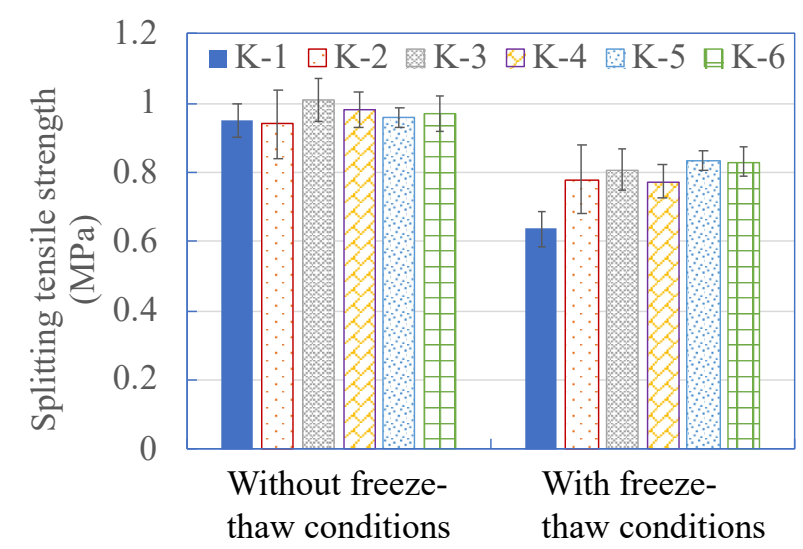

Fig. 3 The effect of freezing and thawing on split tensile strength

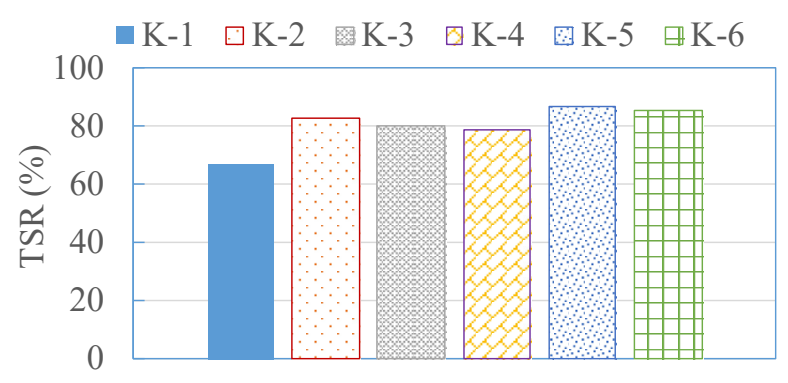

(b) $\mathrm{C} 40$ concrete

Fig. 4 Splitting tensile strength ratio (TSR) of different test samples

\subsection{Immersion rutting test}

Traffic load is also one of the main reasons for the deterioration of water stability of asphalt binder. From the perspective of macro mechanics, asphalt pavement structure needs to face the repeated action of traffic load in the service process; at this time, the interface between asphalt and aggregate will have repeated shear action, and different aggregate particles will also have repeated shear action. If the interface between asphalt and aggregate has shear failure, the water can quickly enter between the interface of asphalt and aggregate through the point of shear failure, resulting in the deterioration of water stability of asphalt binder. On the other hand, when the water enters the asphalt binder, under the repeated load, the ordinary water becomes dynamic water, which further accelerates the deterioration of water stability of asphalt binder. Therefore, the immersion rutting test was used to further study the water stability of the medium weathered igneous rock asphalt binder under load.

The results of immersion rutting test under different test schemes to improve the binding performance of asphalt and aggregate were shown in Figure 5.It could be seen that the rutting depth curve of immersion rutting test showed an obvious slope change at $10 \mathrm{~min}$. In the first 10 min of immersion rutting test, the rutting depth of each test group increased greatly, and then the rutting depth of each group showed a linear relationship with the extension of immersion time, with a small increase.

For the K-1 group without anti-stripping measures, the rutting depth was the largest in the rutting test of each immersion time, which indicates that the application of medium weathered igneous rock in asphalt binder needs to take anti-stripping measures to improve its water stability. The rutting depth of each test group with different technical measures within 10 minutes of immersion was basically similar, and then with the extension of immersion time, the rutting depth of K-2 group with anti-stripping agent was deeper than that of other groups, which indicated that the durability of water stability of medium weathered igneous rock asphalt binder with anti-stripping agent was relatively poor. In the 60 min immersion rutting test, the K-5 test group with cement and anti-stripping agent mixed had the shallowest rutting depth, which indicated that the medium weathered igneous rock asphalt binder with cement and antistripping agent mixed had the strongest resistance to deformation.

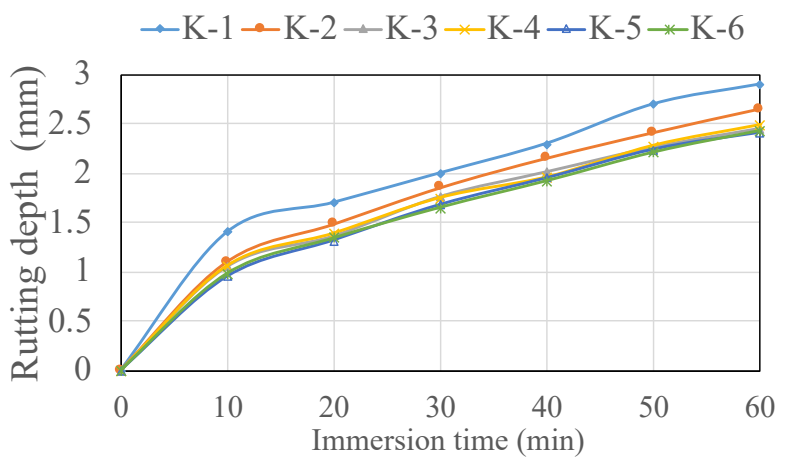

Fig. 5 Result of Immersion rutting test

\section{Conclusion}

(1) The 48h Marshall residual stability of the benchmark asphalt binder without any measures was $78.5 \%$, which did not meet the standard requirements. The Marshall residual stability of medium weathered igneous rock could be significantly improved by adding anti-stripping agent, cement and hydrated Lime.

(2) After the freezing and thawing cycles of the medium weathered igneous rock asphalt binder, the split tensile strength decreased significantly. The TSR value of the asphalt binder with anti-stripping technical measures was K-4, K-3, K-2, K-6 and K-5 in order from small to large.

(3) Single mixing of anti-stripping agent, cement and hydrated Lime could greatly increase the TSR of medium weathered igneous rock asphalt binder. Single mixing of anti-stripping agent has the best effect, and single mixing of cement had better effect than hydrated Lime. Through compounding anti-stripping agent and with cement or hydrated Lime composite, the water stability of the medium weathered igneous rock asphalt binder was most significantly improved.

(4) The durability of water stability performance of medium weathered igneous rock asphalt binder with antistripping agent was relatively poor, while that of medium weathered igneous rock asphalt binder with cement and anti-stripping agent was the strongest. 


\section{Acknowledgements}

This research was funded by National Natural Science Foundation of China, grant number 51978408, and National Key R\&D Program of China, grant number 2016YFC0701000.

\section{References}

[1] S. Dong, S. Han, Y. Yi, S. Wu, and Q. Zhang, J. Chongqing Jiaotong Univ. Sci. 40, 89 (2021).

[2] J. Tan, West. China Commun. Sci. Technol. 21 (2018).
[3] Z. Wei, Transp. Sci. Technol. 132 (2017).

[4] Y. Wu, F. Wang, and Y. Zhang, J. China Foreign Highw. 36, 289 (2016).

[5] D. Wu, The Research of Performance on Cement and Amine Anti-Stripping Material's Asphalt Mixture Pavement, Dissertation, Chongqing Jiaotong University, 2016.

[6] S. Du and X. Suo, J. Xi' an Technol. Univ. 33, 982 (2013).

[7] X. Zheng, Q. Yang, and W. Lv, J. Build. Mater. 480 (2005). 